\title{
The Barbary Macaque in North Africa
}

\author{
David Milton Taub
}

Destruction of the native forests is the chief reason for the decline of the Barbary macaque Macaca sylvanus in Morocco and Algeria, its last wild refuges. (This is the monkey that occurs in a semi-wild state on Gibraltar.) The wild populations now are mostly small and widely separated, and the few that are in protected areas are unfortunately not the most viable. The author spent 15 months on a behavioral study of the macaque in Morocco in 1973-74, and three months on a survey in both countries, partly aided by an FPS Oryx $100 \%$ Fund grant. After his report, which underlines the urgency of protecting some of the Middle Atlas cedar forests, was presented the Moroccan Government inivited him to advise them on wildlife management and conservation programmes, including the development of national parks.

The Barbary macaque Macaca sylvanus is the only one of the thirteen Macaco species that lives outside Asia, and the only nonhuman primate indigenous to North Africa. One of only a few nonhuman primates that live for extended periods in snow-covered areas, it appears to have evolved morphological adaptations for a cold climate, such as lack of a tail and long winter pelage. Only the Japanese macaque Macaca fuscata lives in a more northerly latitude. Moreover, it has a well-developed behavioral pattern of interactions between males and infants that appears to be unique ${ }^{6,21,24}$ Only two field studies of wild populations have been done, one by the author in 1973-1974, and one by Dr John Deag in 1968-1969.4 Historical reports of distribution ${ }^{10,9}$ are general and superficial and current biogeographical data are not available.

From December 1974 to February 1975, and also during several short intervals in the behavioural study, the author conducted a census survey and mapped distribution in Morocco and Algeria; a detailed report ${ }^{22}$ was submitted to the Fauna Preservation Society and a brief summary published in Oryx. ${ }^{17}$ A modified version of this report, detailing the geographical distribution and discussing habitat diversity, has been published. ${ }^{23}$ This paper outlines the species' current distribution and up-dates its present conservation status.

\section{Distribution in Morocco}

There are three distinct and disparate Barbary macaque populations in Morocco: in the High Atlas, the Rif and the Middle Atlas. Several historical accounts suggest a widespread distribution in the High Atlas in the early part of the 20 th century ${ }^{1,3}$ but in 1968 Deag and Crook could find monkeys only in the Ourika valley region of the High Atlas, $50 \mathrm{~km}$ SSE of Marrakech.6 Independent foresters' reports indicate that today only a relict population survives, confined to the riverine habitat of this valley. As Deag suggests, this appears to be the southern and western limits of the species's current range. ${ }^{4}$

In the mountainous region of the Rif there has been extensive deforestation over the past 40 years, and the remaining forests, which include evergreen oak Quercus ilex, cork oak $Q$. suber, the rare Moroccan fir Abies pensapo, and 


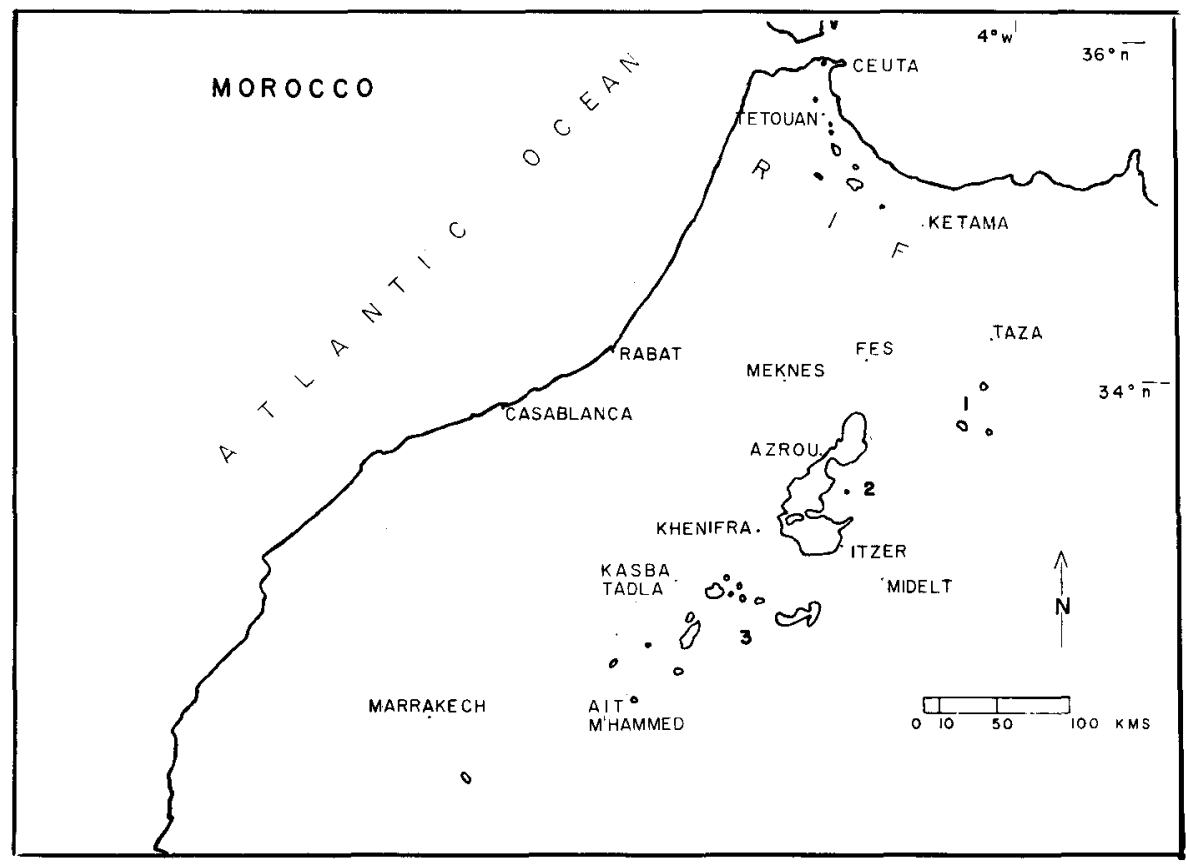

Distribution in Morocco

cedar Cedrus atlantica, are small, discontinuous and open. According to historical reports monkeys have never been numerous in the Rif, although their range was more extensive earlier in this century than now. Today, they are restricted to no more than ten isolated forest pockets in the Djebala region (the north-west chain) of the Rif, and several of these are in poor-quality marginal habitat supporting essentially relict groups of under 25 animals each. The main one is the Djebel (hill/mountain) Lakraa (ca 4000 ha, elevation $1700-2000 \mathrm{~m}$ ), which supports fewer than 50 animals. I estimated that only 300 to 400 monkeys survive throughout the entire Rif today.

Some of North Africa's finest remaining forests are in the Middle Atlas mountain range, and there the macaques reach their highest density and greatest abundances (Table 1) in three distinct and separate zones - eastern, central and southern. (Areas 1, 2, and 3 on the map.) In the eastern zone only small, relict populations survive in three constricted sites of marginal habitat, probably not more than 150 animals. The central zone has the finest high $(2000 \mathrm{~m}+)$, mixed cedar and evergreen oak forests of North Africa, varying from dense, closed canopy stands of cedar and evergreen oak, the macaque's preferred habitat, to thin covers of scrub oak. Their distribution in this zone is uneven, ranging from $40-70$ per $\mathrm{sq} \mathrm{km}$ in the mixed cedar areas around Ain Kahla down to low concentrations, e.g. around Immouzer-du-Kandar. But they occur throughout the forests of this region and I estimated numbers at between 7000 and 14,000, over 80 per cent of the Moroccan total.

The southern zone soils tend to be poor so that the forests are neither as 


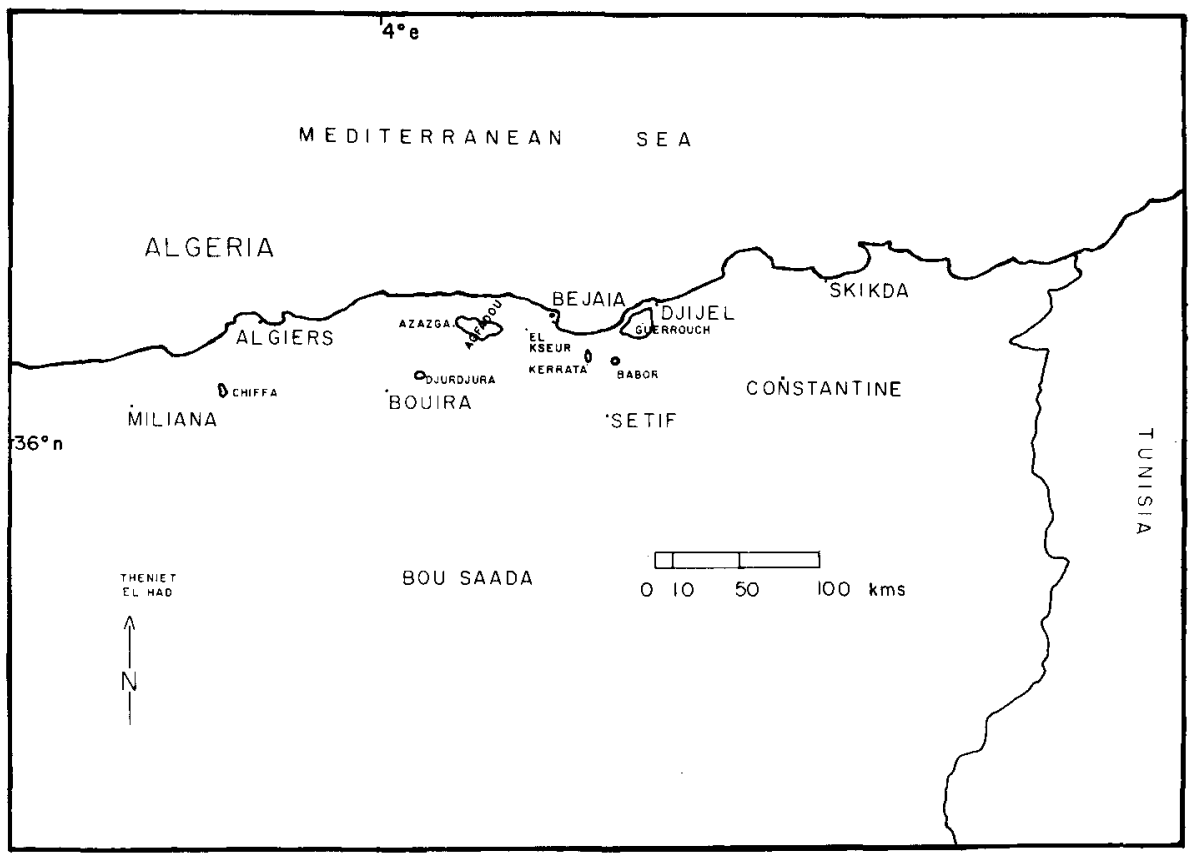

Distribution in Algeria

extensive nor of as high quality. The region is dominated by evergreen oak forests, although some cedar occurs in the eastern part. Macaque distribution is patchy, and densities are typically low, although numbers, comparable to similar regions of the central zone, occur in the dense evergreen oak forests around El Ksiba. I estimated the southern zone monkeys at about 2000.

In Morocco the discontinuous and highly disjunct pattern of Barbary macaque distribution is related to forest distribution and quality. Almost three-quarters of the world population occurs in Morocco (Table 1), and about 80 per cent of these are concentrated in the Middle Atlas montane forests. This disproportionate concentration appears to be correlated with the only modest expanse of continuous, high-quality cedar and oak forests to be found in the macaque's range.

\section{Distribution in Algeria}

In Algeria the macaque is confined to a few restricted areas in the eastern coastal mountain ranges of the Grande and Petite Kabylie. One is on the inaccessible slopes of the Gorge de Chiffa, about $60 \mathrm{~km}$ south of Algiers, where there are under 300; another is the 70-ha Pic des Singes National Park above the city of Bejaia, where there are about 50 . Before the 1930s monkeys were plentiful and widespread in the cedar and oak forests of the Djebel Djurdjura of the Grande Kabylie range, ${ }^{10}$ but these forests have been drastically reduced and since 1967 monkeys have been restricted to the Tigounatine forest (1750-1850 m; less than $1000 \mathrm{ha})$, where fewer than 500 survive. Between Azazga and El Ksuer is a large oak zone, contain- 
Portuguese Quercus faginea and afares $Q$. afares oaks, and here the largest monkey concentrations occur, the highest densities being in the pure Portuguese oak above $1000 \mathrm{~m}, \mathrm{e} . \mathrm{g}$. Agfadou. Numbers there are comparable to 'medium' indices for Moroccan Middle Atlas populations. In the 10,000+ ha of this mixed oak zone, I estimated that about 2000 animals survive, and in the entire Grande Kabylie range between 2300 and 3500 .

In the Petite Kabylie mountain range there are three areas for macaques that are virtually identical with the Grande Kabylie habitats; scrub vegetation gorges, high mixed cedar forests, and mixed oak forests. There appear to be fewer than 200 animals in the Chabet el Akra, the Gorge of Death, and, as in the analogous habitat at Chiffa, the animals are restricted to the inaccessible steep slopes within the gorge. In the Djebel Babor National Park $(2000 \mathrm{~m}$; $1700 \mathrm{ha}$ ) there is a broken impoverished cedar forest, similar to the Djurdjura forests, where I estimated about 300 animals. In the mixed oak belt, analogous to that at Agfadou, on the Mediterranean coast SSW of Djijel, the highest monkey concentrations are limited to the higher parts where the forest is mainly pure Portuguese oak, e.g. Guerrouch. But due to extensive logging operations, the monkey populations were less numerous than at Agfadou, an opinion shared by local foresters, although the two regions are similar in size and composition.

The discontinuous distribution pattern so characteristic in Morocco is even more pronounced in Algeria. Monkeys occur in only seven sites, all widely separated, of which only two, the mixed oak forests of Agfadou and Guerrouch (ca 10,000 + ha each) support even modest numbers representing 90 per cent of the Algerian population. The other five are all quite small and support only small, essentially relict populations (Table 1).

\section{Prehistory and Historical Distribution}

The history of the Cercopithecidae family in Europe dates from the Miocene, ${ }^{7}$ and although there is considerable uncertainty about the exact interpretation of the fossil record, it appears that only two or three types of Cercopithecids ranged through Europe in pre-Pleistocene times. The genus Macaca was probably European in origin. Kurten suggests that $M$. florentina is ancestral to the Barbary macaque, and if fossil materials dating from 1 million to $\frac{1}{2}$ million years are considered transitional, then the middle Pleistocene ushers in the essentially modern forms of Macaca sylvanus. For example, Owen's middle Pleistocene $M$. pliocaenia ${ }^{18}$ is believed to be conspecific with the modern Barbary macaque ${ }^{20}$, and other fossils assigned to the modern species date from the Halstenien interglacial phases, i.e. between 400,000 and 230,000 years ago. ${ }^{13}$ The paucity of fossil data makes it difficult to pinpoint the time when Asiatic and Barbary macaques separated (Delson, quoted in Deag $\left.{ }^{5}\right)$ but on the existing fossil record it is reasonable to hold that $M$. sylvanus radiation dates from the European middle Pleistocene period. The history of its subsequent spread through Europe and the circumMediterranean region is as yet unknown; fossil sites substantiate that at least by the late Pleistocene the species had spread from the British Isles through Europe and across north Africa from Morocco to western Egypt. ${ }^{16}$ Fossil material held in the British Museum (Natural History) ( $P$. Napier, pers. comm., 1976) confirms that the Barbary macaques occurred as far north as the British Isles at least as recently as 5000 years ago, and archaeological sites at 


\section{Table 1. Summary of Population Estimates in Morocco and Algeria}

\begin{tabular}{|c|c|c|c|}
\hline Area & $\begin{array}{l}\text { Minimum to maximum } \\
\text { population estimates }\end{array}$ & $\begin{array}{l}\dagger \text { Per cent of } \\
\text { country total }\end{array}$ & $\begin{array}{l}\text { * Per cent of } \\
\text { world total }\end{array}$ \\
\hline Morocco: & $12,150-16,550$ & & $0 \cdot 74$ \\
\hline High Atlas & less than 50 & 0.00 & 0.00 \\
\hline Rif & $300-400$ & 0.05 & 0.02 \\
\hline Middle Atlas & $9150-16,150$ & 0.95 & $0 \cdot 70$ \\
\hline Eastern zone & less than 150 & 0.00 & 0.00 \\
\hline Central zone & $7000-14,000$ & $0 \cdot 82$ & 0.60 \\
\hline Southern zone & less than 2000 & 0.18 & 0.09 \\
\hline Algeria: & $4150-5850$ & & $0 \cdot 26$ \\
\hline Chiffa & less than 300 & 0.05 & 0.01 \\
\hline Grande Kabylie & $2350-3550$ & 0.59 & $0 \cdot 15$ \\
\hline Petite Kabylie & $1500-2000$ & 0.33 & 0.09 \\
\hline
\end{tabular}

Carrickfergus, North Ireland, dated 1400 AD, contains $M$. sylvanus fossils. However, Dr Napier believes that these fossils represent imported domestic pets, and that there were no natural populations in the British Isles at this time. In 1894 Lydekker wrote that the macaque 'is also found across the straits of Gibraltar and (in) some of the neighboring parts of Spain ...', suggesting that by the end of the 19th century its European distribution was restricted to the Rock of Gibraltar and isolated pockets in southern Spain. The only European site since the early 20 th century, and there are several accounts of its history there $14,12,26,15$ is reported to be Gibraltar. But exactly when the European populations disappeared remains an unresolved question.

Several reports suggest that the macaque occurred as far east as Libya and Egypt, where it arrived in the late Pleistocene, as late as the mid-19th century, ${ }^{19,1}$ but there appears to be little direct confirmation of this. It appears certain, however, that by the latter part of the 19 th century they had become extinct east of Tunisia, although until the last decade of the 19th century they may still have occurred sporadically in Tunisian coastal forests. ${ }^{10}$

A comparison of historical accounts of Barbary macaque distribution $^{25,2,10,3,8,9}$ with today's situation shows a pattern of range reduction and elimination. In Morocco, where once they were widely spread through the High Atlas, from Tizi-n-Test through the Ourika valley and eastward, ${ }^{10}$ today only a relict population survives restricted to the Ourika valley. They were also found in the eastern Rif, in the cedar forests surrounding Ketama (as late as 1968; J. Chitty, pers. comm., 1974) extending eastward to Al Hoceima (1920s), where today there are none. In Algeria, they have apparently disappeared within the last 15 years from the Rond-Point des Cèdres at Thenient el-Had, from Chrea, and from the forests surrounding the forestry post at Tighret, $25 \mathrm{kms} \mathrm{NW}$ of Miliana (J. Thomas, pers. comm., 1975), and there are several areas in the Kabylie de Collo, east of the Petite Kabylie, where monkeys occurred ${ }^{10}$ but are now absent.

It is difficult to ascertain population densities and abundances from the general and often anecdotal historical accounts, but it is clear that in the past 
45 years their range has diminished, numbers have fallen, and they have disappeared from previously occupied areas in both countries. The principal cause has been deforestation by man. ${ }^{10},{ }^{11} \cdot{ }^{26},{ }^{5},{ }^{22}$ Sport hunting, crop control or use for food may also have contributed in some areas, e.g. the eastern Kabylie and the Rif ${ }^{10,11,5}$.

In both Morocco and Algeria, the Barbary macaque's diminution in range and numbers continues, and present trends threaten further decreases. Their world population is not more than 23,000 animals (Table 1). Most areas of occupation are small, and several represent marginal habitats which support only small, unstable populations, unable to expand because of their restriction to poor habitats. The one area where they have a moderately extensive distribution with high abundance (comparable with other macaques and baboons) is the Central Middle Atlas zone. This is essentially the last refuge for this macaque's survival.

In both countries the most serious threats to the species's continued survival derive from officially sanctioned commercial logging programmes. In Algeria, the Portuguese, cork and evpergreen oaks are commercially logged wherever they occur; in Morocco, the evergreen oak is clear-cut almost everywhere, and the cedar is extensively logged in the Middle Atlas. Illegal cutting, especially of evergreen oak, also occurs. The evergreen oak is allowed to regenerate naturally, unless the clear-cut area is given over to agriculture. Morocco has a modest programme of cedar reforestation, but Dr Deag ${ }^{5}$ and I both believe it is insufficient to keep pace with the logging. The heavily exploited mixed cedar forests are the macaque's preferred habitat, so that even the densest populations are not safe. At present exploitation rates, primary habitats will continue to be irreplacably reduced in both countries with an accompanying decline in monkeys.

Hunting and capture for sale to tourists does not appear to be a serious problem, but capture for export could be. At least 400 monkeys have been exported from Morocco in the last seven years, principally to European wildlife parks, ${ }^{5}$ and Deag admits this is an underestimate; at least 50 animals he has not mentioned were taken by a French park group during my study period in the summer of 1974. Although most of the animals exported in recent years appear to have been captured from areas where monkeys are numerous (i.e. the Middle Atlas), continued captures of this magnitude would be a serious drain on Moroccan populations. In Algeria Deag reports that several institutes intend to capture animals for biomedical research. Because all Algerian populations are small and in fairly restricted habitats, even modest capture programmes could be a severe threat to the macaque's survival there.

My conclusions from this study are that the Barbary macaques continue to decrease, both in numbers and range, and that unless current patterns are reversed both trends will continue and the outlook for the species is a gloomy one.

\section{Conservation Measures}

The Algerian government recognises that the Barbary macaque is an endangered species; it is now officially protected and may not be captured, killed or exported. 5 Several macaque areas are included in national parks, which unfortunately tend to be small (less than $1000 \mathrm{ha}$ ) and do not include any areas of high macaque density so that they are insufficient to provide for 


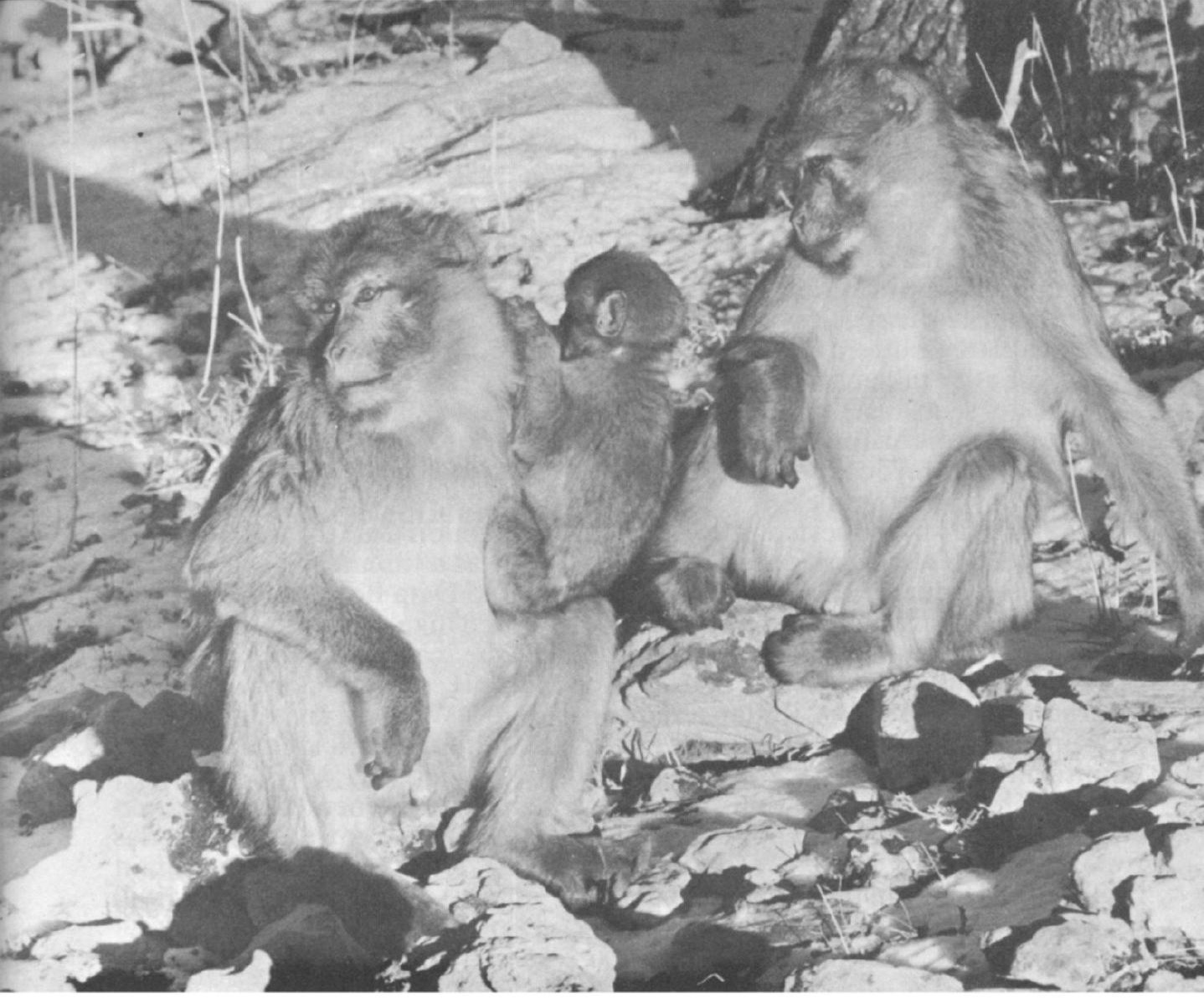

SUBADULT MALES looking after an infant, a typical type of care-taking response among Barbary macaques

the long-term conservation of the species. Moreover, and equally important, the Algerian Forestry Service is severely short of well trained, middle-echelon managerial personnel, and the implementation of the well intentioned national parks programme suffers accordingly. These modest conservation efforts do not affect the continued destruction of primary habitat by logging.

Morocco does not have a national parks programme. The Forestry Department regards macaques as 'common' and they are not officially protected (although Deag's reports that 'they have been protected by law for some time'). Apparently it has been easy to capture and export macaques in quantities of under 100 animals in the recent past. In 1974, the Moroccan government invited a United Nations Development Project under the auspices of the Food and Agriculture Organisation (FAO) into Morocco to formulate guidelines for an official national parks programme and to establish several parks in unique ecozones, but in 1976, due to a budget crisis, the FAO project ceased operation without setting up a programme. The Moroccan government itself now appears to be taking the initiative and has established a new department concerned solely with fauna conservation within the Forestry Service. This department has invited the author to act as a consultant and to advise and assist in the development of wildlife management and conservation 
programmes. It is hoped that in the next few years an official programme for wildlife conservation, including national parks, will be established.

The recommendations in the author's detailed report, ${ }^{21}$ which was sent to the Forestry Services of both countries, included the following recommendations for the Barbary macaque:

1. prohibit all capture and trade, except for legitimate conservation purposes;

2. reintroduce the species into protected areas within its former range;

3. re-evaluate and reformulate commercial logging programmes and reduce the quantity taken annually;

4. institute specialised training programmes in wildlife management and conservation for foresters;

5. initiate (in Morocco) and expand (in Algeria) national parks and wildlife sanctuary programmes.

The author also requested the International Union for Conservation of Nature (IUCN) to classify the Barbary macaque as a threatened species, and this has been done. In the revised edition of the Red Data Book the macaque is categorised as 'vulnerable', defined as: 'believed likely to move into the endangered category in the near future if the casual factors continue operating'. It is also listed in the Appendix II of the Convention on International Trade in Endangered Species of Wild Fauna and Flora, meaning that trade between acceding nations is subject to strict regulation and monitoring of its effects.

If some of the recommendations are accepted and implemented in Morocco and Algeria, particularly if populations in the Moroccan Central Middle Atlas zone are protected, there is every reason to believe the species can maintain itself satisfactorily in the future. But if not this unique non-human primate will very likely be extinct by the end of the 20 th century.

\section{Addendum}

During the summer of 1977, the author, with Dr J. A. Kurland of Pennsylvania State University, was charged by the Director of the Eaux et Forêts (Moroccan Forestry Service) to prepare detailed proposals for wildlife management and conservation and the development of national parks. We surveyed several of the most promising areas in the high mixed cedar forests of the Middle Atlas regions for park status, and our report will recommend at least two, of about 3500 and 4000 ha each, at Ifrane/Rass-el-Ma and Ain Kahla. This proposal will provide a foundation for a modest but realistic national parks programme. It now remains for the Government itself to pursue the guidelines set down for the preservation of the country's ecosystems.

\section{Acknowledgments}

I would like to acknowledge financial support from Mrs Pam Taub, the National Science Foundation (GB\#37497), Rockefeller Foundation, Explorers' Club of New York, the New York Zoological Society, and the Fauna Preservation Society of Great Britain (Oryx 100\% Fund). I am indebted in numerous ways to the following individuals and institutions: Dr William A. Mason, Forestry Services of Algeria and Morocco, and M. Zaki, Directeur, Eaux et Forêts (Morocco); Ms Marian Cast, Dr Peter Rodman, Dr John M. Deag, John Chitty, Dr J. P. Thomas, Dr Jeffrey Kurland, and Dr A. Whitten. 


\section{References}

1. BARTH, H. 1849. Wanderungen durch die Kustenländer Mittelmeeres, 1845-7. Berlin.

2. BEDE, P. 1926. Notes sur l'ornithologie du Maroc. Mem. Soc. Sci. nat., Maroc 16, $28-30$.

3. CABRERA A. 1932. Los mamiferos de Marruecos. Trab. Museo Nac. Cienc. nat. Ser. zoo. 57, 200-208.

4. DEAG, J.M. A study of the social behaviour and ecology of the wild Barbary macaque, Macaca sylvanus L. PhD dissertation. Univ, of Bristol, England.

5. 1978. The status of the Barbary macaque Macaca sy/vanus in captivity and factors influencing its distribution in the wild. In Primate Conservation. G.H. Bourne and Prince Rainier (eds.). Academic Press, New York.

6. — and H.H. CROOK 1971. Social behaviour and 'agonistic buffering' in the wild Barbary macaque, Macaca sylvana L. Folia primatol. 15, 183-200.

7. DELSON, E. and P. ANDREWS 1975. Evolution and interrelationships of the catarrhine primates. In Phylogeny of the Primates, W. Luckett and F. Szalay (eds.). Plenum Press, New York.

8. DIDIER, R. and P. RODE 1936. Mammifères, étude systematique par espèces, II Macaca sy/vanus. Paris.

9. HEIM DE BALSAC. H. 1936. Biogéographie des mammifères et des oiseaux de l'Afrique du nord. Bull. biol. Franc et de Belgique, Paris, suppl. 21, 82-83.

10. JOLEAUD, L. 1931. Etudes de géographie zoologique sur la Berberie. Les primates: le magot. Congr. Intern. de Geogr, Paris, Trav. de la Sect. III.

11. __- 1931. Le rôle des singes dans les tradition populaires nord africains. J. Africanistes 1 , $117-150$.

12. KENYON, E.R. 1938. Gibraltar under Moor, Spaniard and Briton. London.

13. KURTEN, B. 1968. Pleistocene Mammals of Europe. Weidenfeld and Nicolson, London.

14. LYDEKKER, R. 1894. The Royal Natural History, Vol. 1. Warne, London.

15. MORRIS, D. and R. 1967. Men and Apes. Hutchinson, London.

16. OSMAN-HILL, W.C. 1974. Comparative anatomy and taxonomy. VII: Cynopithecinae; Cercocebus, Macaca, Cynopithecus, Wiley, New York.

17. ORYX, anon. 1976. A bleak outlook for Barbary apes. Notes \& News. Oryx 13, 229

18. OWEN, R. 1865. On a new genus (Miolophus) of mammal from the London clay. Geog. Mag. 2. 339-341.

19. RÜPPELL, E. 1835-40. Neue Wirbelthiers zu der Fauna von Abyssinien gehörig. S. Schmerber, Frankfurt-a-M.

20. SIMONS, E.L. 1972. Primate Evolution. Macmillan, New York.

21. TAUB, D.M. 1975. Paternalism in free-ranging Barbary macaques, Macaca sylvanus L. Paper presented at the ann. meetings of the Amer. Assn. Phys. Anthrop., Denver. Abstract: Amer. J. Phys. Anthrop. 42, 333-334.

22. TAUB, D.M. 1975b. A report on the distribution of the Barbary macaque Macaca sylvanus in Morocco and Algeria. Unpublished report submitted to the IUCN, New York Zoological Society and the Fauna Preservation Society. $71 \mathrm{pp}$ mimeo.

23. - - 1977, Geographic Distribution and Habitat Diversity of the Barbary Macaque Macaca sylvanus L. Folia primatol. 27: 108-133.

24. 1978, Aspects of the Biology of the Wild Barbary Macaque (Primates, Cercopithecinae, Macaca sylvanus L 1758): Biogeography, The Mating System and Male-infant Associations. Unpublished PhD dissertation. Univ. of California, Davis.

25. TROUESSART, E.L. 1900. La faune des mammifères de l'Algérie du Maroc et de la Tunisie. Caus. Sci. de la Soc, zoo. de France 1, 353-410.

26. ZEUNER, F.E. 1952. Monkeys in Europe, Past and Present. Oryx 1, 265-273.

David Milton Taub. Department of Comparative Medicine, Bowman Gray School of Medicine of Wake Forest University, Winston-Salem, North Carolina 27103, USA.

\section{Thailand's Conservation Plan}

Thailand, with the help of IUCN and UNEP, is drawing up a comprehensive nature conservation plan, scheduled for adoption in September 1978. It is intended to examine present national parks and reserves and propose new ones, to assess ecosystems that lie outside the parks, to rehabilitate degraded areas, to coordinate forestry practices with conservation, and to consider environmental impact statements, conservation teaching in schools, fund-raising, restructuring of Government agencies and changes in legislation. 